Energy Research Journal 1 (2): 87-90, 2010

ISSN 1949-0151

(C) 2010 Science Publications

\title{
Performance of Difference Electrode Materials in Electrical Discharge Machining of Tungsten Carbide
}

\author{
${ }^{1}$ P. Janmanee and ${ }^{2}$ A. Muttamara \\ ${ }^{1}$ Department of Industrial Engineering, \\ Rajamangala University of Technology Krungthep, Bangkok 10120, Thailand \\ ${ }^{2}$ Department of Industrial Engineering, Thammasat University, \\ Klongluang Pathumthani 12120, Thailand
}

\begin{abstract}
Problem statement: Electrical Discharge Machining (EDM) is now a well-established machining option in many industries. Tungsten carbide (WC-Co) is an important tool and die material mainly because of its high hardness, strength, wear resistance and high melting point. Normally, EDM is capable of machining geometrically complex or hard material component, that are precise and difficult to machine. The objective of this research is to study the performance of different electrode materials on tungsten carbide workpiece with EDM process. Approach: The electrode materials were graphite (Poco EDM-3), copper-graphite (Poco EDM-C3) and copper-tungsten (solid).The important parameters were discharge current, on time, off time, open-circuit voltage and electrode polarity. A workpiece material was a tungsten carbide (W 90-Co10). Results: The results show that the electrode negative polarity performs very well, Poco EDM-3 gives higher Material Removal Rate (MRR). Both powder electrode (EDM-3 and EDM-C3) give the better MRR and EWR more than solid electrode. Conclusion: The suitable duty factor is $11 \%$. The Surface Roughness (SR) of copper-tungsten give the best when current peak intensity not over 20 amperes.
\end{abstract}

Key words: EDM, performance electrode, tungsten carbide, MRR, EWR, SR

\section{INTRODUCTION}

Electrical Discharge Machining (EDM) is a machine that is used as non-traditional manufacturing and this machine is continually developing further technology that would be impossible to produce with faster and conventional (Mahdavinejad and Mahdavinejad, 2005). This machine produces tools with complex-shapes and being used extensively in industries. Furthermore EDM can operate as surface finish in last stage of tool production (Puertas et al., 2004).

Tungsten carbide (WC-Co) is an important tool and die material mainly because of its high hardness, strength and wear resistance. The melting point of tungsten carbide is $2,800^{\circ} \mathrm{C}$. Due to its properties, it cannot be processed easily by conventional machining technique (Singh et al., 2004). So EDM process will open up an opportunity for the machining of tungsten carbide. Tungsten carbide is some kind of cemented carbide; the particle of carbide is bind with the process of powder metallurgy (George et al., 2004), such as Tungsten carbide (WC-Co), Titanium Carbide (TaC).
In an EDM operation, it is need to select right parameters for sparking performance (Lee and $\mathrm{Li}$, 2003). However, the right and desired parameters that base on the experience, instruction manual or a large number of test of experiment that require a lot of time and materials. The objective of this research is to study the performance of different electrode materials on tungsten carbide workpiece with EDM process.

\section{MATERIALS AND METHODS}

Raw material: The workpiece material was a tungsten carbide with $90 \%$ of $\mathrm{W}$ and $10 \%$ of Co. The electrode materials were graphite, copper graphite and copper tungsten. The workpiece material from United Tungsten Co, Ltd. which is show in Table 1.

The electrode materials were graphite (EDM-3), copper-graphite (EDM-C3) and copper-tungsten (solid). The graphite and copper graphite electrode were bought from Poco Graphite Co, Ltd. The electrodes were made of powder metal. The copper tungsten is made of solid copper tungsten electrode. The physical properties of materials electrode which is show in Table 2.

Corresponding Author: P. Janmanee, Department of Industrial Engineering, Rajamangala University of Technology Krungthep, Bangkok 10120, Thailand 
Sample preparation: The experiment of materials electrode diameter is $3 \mathrm{~mm}$ and depth of EDM spark is $3 \mathrm{~mm}$. The machine is used as a numerical control model FORM-2-LC Charmilles Technologies (Fig. 1). Dielectric oil of spark is Shell EDM Fluid 2A from Shell Co, Ltd. (Thailand). For this experiment of research, to start at determine try-out of suitable parameter relative in EDM process, such as polarity, duty factor, on time, off time, open circuit voltage, discharge current and electrode materials type. The detailed machining conditions used in this investigation were given in Table 3. Finally, the experiment result comparative the optimal parameters of material removal rate, electrode wear ratio, surface roughness. However, the optimal EDM parameter are considered.

Table 1: Physical properties of tungsten carbide

\begin{tabular}{ll}
\hline Properties & Tungsten carbide (WC) \\
\hline Melting point & $2,800^{\circ} \mathrm{C}$ \\
Density & $15.7 \mathrm{~g} \mathrm{~cm}^{-3}$ \\
Thermal expansion & $5 \times 10^{-6 \circ} \mathrm{C}$ \\
Hardness & $87.4(\mathrm{HRA})$ \\
Elastic modulus & $648 \mathrm{GPa}$ \\
\hline
\end{tabular}

Table 2: Physical properties of materials electrode

\begin{tabular}{llll}
\hline Properties & $\mathrm{Cu}-\mathrm{W}$ & EDM-C3 & EDM-3 \\
\hline Melting point $\left({ }^{\circ} \mathrm{C}\right)$ & 3,500 & 1,100 & 3,350 \\
Density $\left(\mathrm{g} \mathrm{cm}^{-3}\right)$ & 15.21 & 3.25 & 1.81 \\
\hline
\end{tabular}

Table 3: Experimental conditions

\begin{tabular}{ll}
\hline Working conditions & Descriptions \\
\hline Workpiece & WC-Co \\
Electrode & Cu-W,EDM-C3,EDM-3 \\
Polarity & $(-),(+)$ \\
Duty factor(fixed off-time, $25 \mu \mathrm{s})$ & $7,32,50,67,89(\%)$ \\
On-time & $2,12,25,50,200 \mu \mathrm{s}$ \\
Duty factor(fixed on-time, $25 \mu \mathrm{s})$ & $2,11,33,50,68,93(\%)$ \\
Off-time & $2,12,25,50,200,1600 \mu \mathrm{s}$ \\
Open circuit voltage & $90,250 \mathrm{~V}$ \\
Discharge current & $6,12,25,50 \mathrm{~A}$ \\
Dielectric fluid & Oil (shell fluid 2A) \\
\hline
\end{tabular}

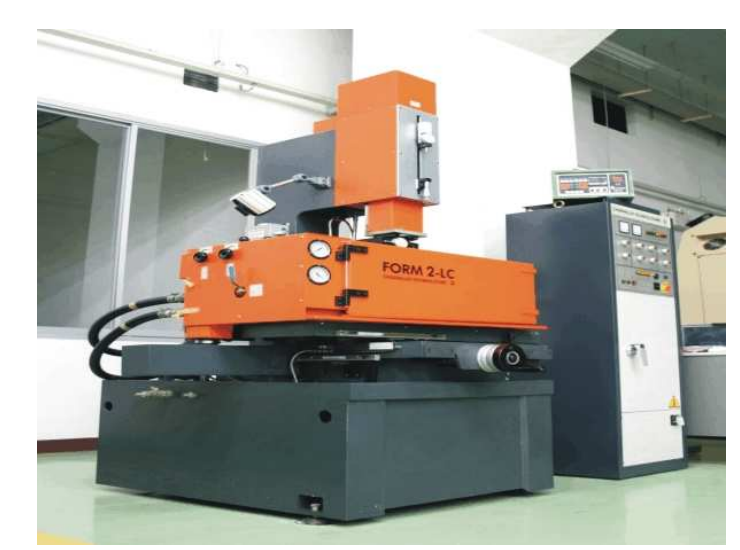

Fig. 1: The CNC machine EDM model FORM-2-LC

\section{RESULTS AND DISCUSSION}

Effect of duty factor (on time): Duty factor is an important for tungsten carbide spark (O'Brien et al., 2003). Duty factor derive from On-time (time to start sparking) and Off-time (time to stop sparking) as following Eq. 1:

Duty factor $(\%)=\frac{\text { On time }}{\text { On time }+ \text { Off time }} \times 100 \%$

Duty factor (\%), on-time, off time $(\mu \mathrm{s})$. Experimental set; on-time, current 6 A, open circuit voltage $90 \mathrm{~V}$, on-time $25 \mu \mathrm{sec}$. As the results of Fig. 3 represent that, lower duty factor have Material Removal Rate (MRR) higher than upper duty factor and negative polarity graphite electrode show the most MRR is $7 \%$.

As Fig. 3, represents positive polarity cuppertungsten electrode has duty factor $89 \%$ at $0 \mathrm{~mm}^{3} \mathrm{~min}^{-1}$ and the same this condition in Fig. 2 has not results because of an inappropriate sparking condition that is not able to produce a material removal rate.
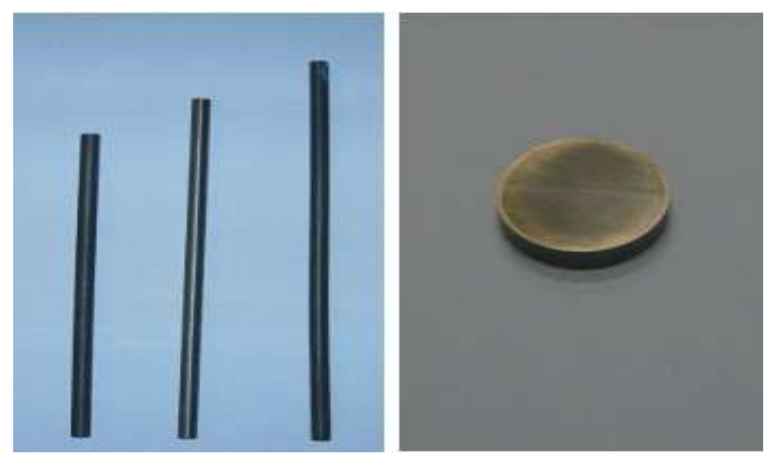

Fig. 2: The electrode (Cu-W, EDM-C3, EDM-3) and workpiece material (WC-Co)

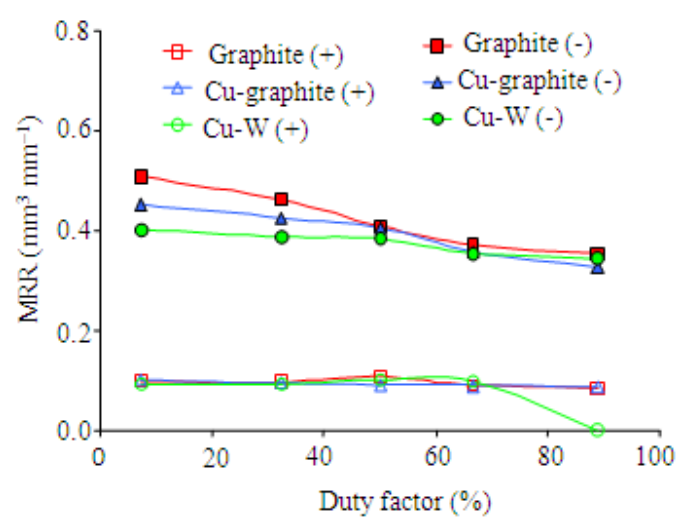

Fig. 3: Duty factor (variation of on-time) and MRR 
Energy Rec. J. 1 (2): 87-90, 2010

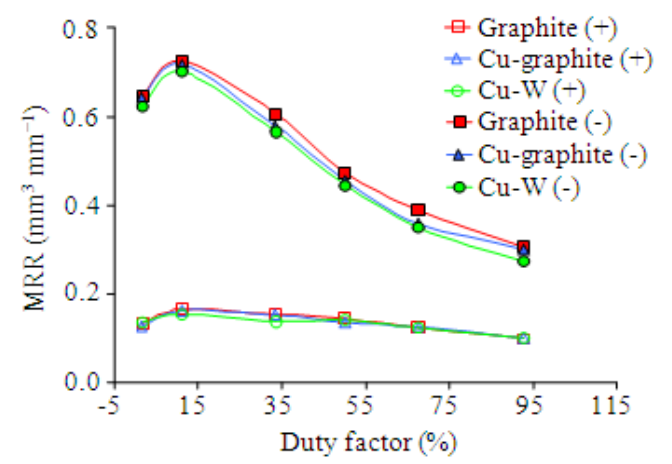

Fig. 4: Duty factor (variation off-time) and MRR

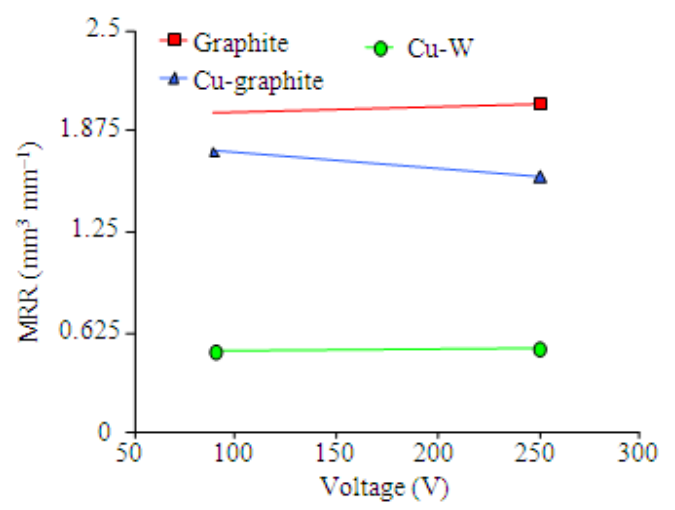

Fig. 5: The relation diagram between open circuit voltages and MRR

Effect of duty factor (off time): As the results of Fig. 4 experimental parameter; current 6 A, Open circuit voltage $90 \mathrm{~V}$ and off time $25 \mu \mathrm{sec}$. As the results of duty factor with variation of off-time, show that the lower duty factor have a higher material removal rate too and when they are compared with values of on-time condition can be represented that their material removal rate have a higher value significantly. Negative polarity graphite electrode has the most MRR $11 \%$.

Effect of open circuit voltage: Previously experiment of a variation of on-time and off-time condition show that negative polarity and graphite electrode are appropriate parameters to sparking carbide tungsten material. Therefore, negative polarity is used only in this experimental procedure. Experimental parameter; current $12 \mathrm{~A}$, duty factor $11 \%$.

Figure 5 and 6 show the results of determining appropriate open circuit voltage parameters, as the results of experiment were found that a variation of open circuit voltage, MRR and electrode wear rate have insignificantly different values, graphite electrode has a maximum MRR and maximum electrode wear rate.

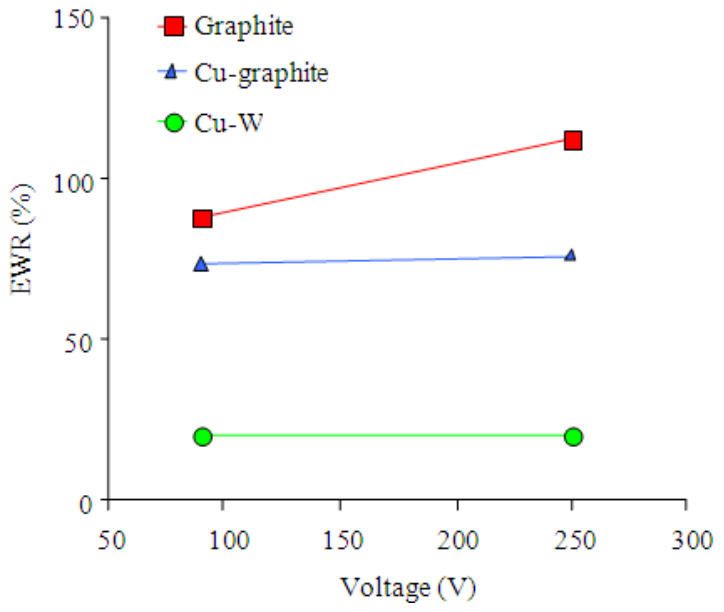

Fig. 6: The relation diagram between open circuit voltages and EWR

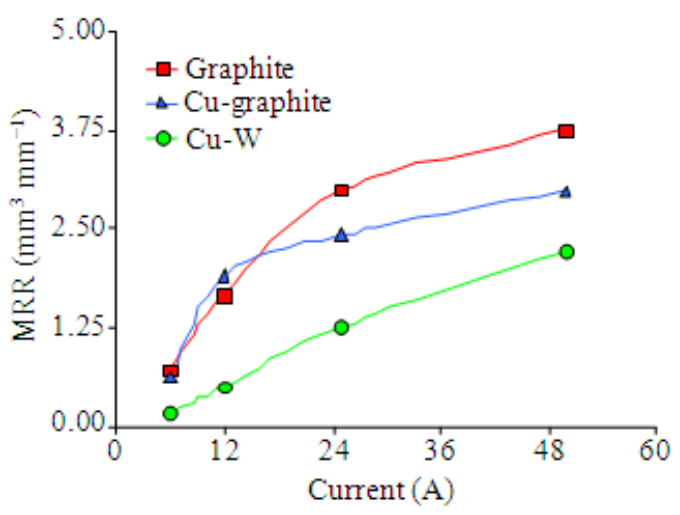

Fig. 7: Variation of EWR with discharge current

Effect of discharge current: Experimental parameter; open-circuit voltage $90 \mathrm{~V}$, duty factor $11 \%$.

Figure 7 shows the relation between current and MRR of workpiece were found that an increased current have influence to increasing of MRR, graphite electrode has the most MRR at $55 \mathrm{~A}$.

Figure 8 shows the relation between current and electrode wear rate of workpiece were found that an increased current have influence to deceasing of electrode wear rate, unless cupper-tungsten is performed, In case of cupper-tungsten electrode has the least electrode wear rate at 6 A. Figure 9 shows the relation between current and rough surface (Lee and $\mathrm{Li}, 2001$ ) were found that an increasing rough of surface have an effect from increased current, cupper-tungsten electrode has the least rough surface at $6 \mathrm{~A}$. 


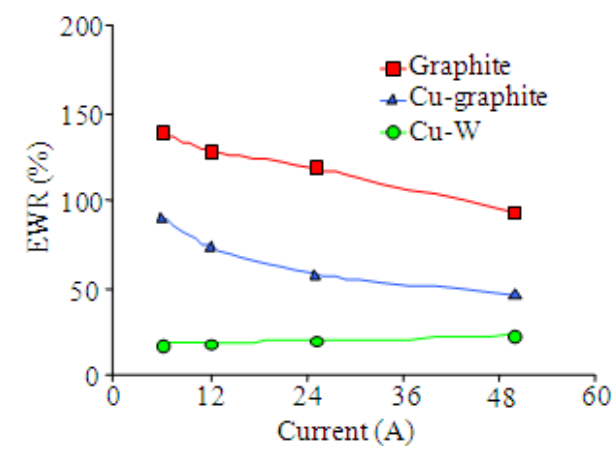

Fig. 8: Variation of discharge current with MRR

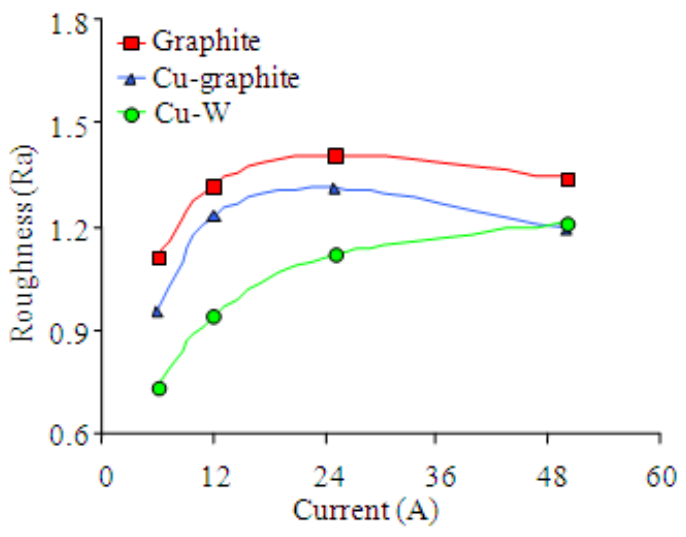

Fig. 9: Variation of discharge current and surfaces roughness

\section{CONCLUSION}

From this research it can be concluded that following below:

- The duty factor value decreased give the less material removal rate and the effectiveness of the process is evaluated of MRR increases with the discharge current intensity

- The graphite electrode gives the most material removal rate and gives the better than surface roughness but it gives high electrode wear ratio.

- The results show that the electrode negative polarity performs very well, Poco EDM-3 gives significantly higher Material Removal Rate (MRR) and lower surface micro-crack density than the Poco EDM-C3 and copper-tungsten

- The material powder electrode (EDM-3 and EDMC3) give the better MRR and less micro-cracks than solid electrode
- The results show optimum of all electrodes same parameters with negative polarity, open-circuit voltage of $90 \mathrm{~V}$, current is $25 \mathrm{~A}$, on time is $25 \mu \mathrm{sec}$ and off time is $200 \mu \mathrm{sec}$

\section{ACKNOWLEDGEMENT}

The researchers are grateful to the National Metal and Materials Technology Center (MTEC), Poco Graphite Co, Ltd and United tungsten Co, Ltd. for supply materials and equipments analysis.

\section{REFERENCES}

George, P.M., B.K. Raghunath, L.M. Manocha and Ashish M. Warrier, 2004. EDM Machining of carbon-carbon composite-a Taguchi approach. J. Mater. Process. Technol., 145: 66-71. DOI: 10.1016/S0924-0136(03)00863-X

Lee, S.H. and X.P. Li, 2001. Study of the effect of machining parameters on the machining characteristics in electrical discharge machining of tungsten carbide. J. Mater. Process. Technol., 115: $\quad 344-358 . \quad$ DOI: $10.1016 /$ S09240136(01)00992-X

Lee, S.H. and X.P. Li, 2003. Study of the surface integrity of the machined workpiece in the EDM of tungsten carbide. J. Mater. Process. Technol., 139: $\quad 315-321 . \quad$ DOI: $\quad 10.1016 / S 0924-$ 0136(03)00547-8

Mahdavinejad, R.A. and A. Mahdavinejad, 2005. ED machining of WC-Co. J. Mater. Process. Technol., 162: 637-643. DOI: 10.1016/j.jmatprotec.2005.02.211

O'Brien, F.J., D. Taylor and T. Clive Lee, 2003. Microcrack accumulation at different intervals during fatigue testing of compactbone. J. Biomech., 36: 973-980. DOI: 10.1016/S0021-9290(03)00066-6

Puertas, I., C.J. Luis and L. Alvarez, 2004. Analysis of the influence of EDM parameters on surface quality, MRR and EW of WC-Co. J. Mater. Process. Technol., 153: 1026-1032. DOI: 10.1016/j.jmatprotec.2004.04.346

Singh, S., S. Maheshwari and P.C. Panday, 2004. Some investigation into the electric discharge machining of hardened tool steel using different materials. J. Mater. Process. Technol., 149: 272-277. DOI: 10.1016/j.jmatprotec.2003.11.046 